\title{
Annealing and temperature dependences of the electrical activity of grain boundaries in germanium observed by SEM/EBIC techniques
}

\author{
N. Tabet $\left({ }^{1, *}\right)$, C. Monty $\left({ }^{1}\right)$ and Y. Marfaing $\left({ }^{2}\right)$ \\ (1) Laboratoire de Physique des Matériaux, C.N.R.S., 1 place A. Briand, 92195 Meudon Cedex, France \\ (2) Laboratoire de Physique du Solide, C.N.R.S., 1 place A. Briand, 92195 Meudon Cedex, France
}

(Reçu le 23 août 1988, révisé le 13 février 1989, accepté le 12 juin 1989)

\begin{abstract}
Résumé. - L'activité électrique des joints de grains dans le germanium polycristallin a été étudiée par la technique SEM/EBIC. L'effet de traitements thermiques successifs $\left(T=810^{\circ} \mathrm{C}, t=2 \mathrm{~h}\right.$ et à $T=400^{\circ} \mathrm{C}$, $t=50 \mathrm{~h}$ ) a été analysé. Des profils de courant EBIC à travers des joints de grains inactifs ont été enregistrés à différentes températures entre 140 et $300 \mathrm{~K}$ et pour plusieurs valeurs de courant primaire. Une inversion de contraste a été observée pour les niveaux d'injection élevés et à basses températures. Cette observation a été associée à une transition de processus piégeage/recombinaison sur un niveau $E_{\mathrm{t}}$ proche de la bande de valence $\left(E_{\mathrm{t}}=E_{\mathrm{v}}+0,03 \mathrm{eV}\right)$.

Abstract. - The electrical activity of grain boundaries in polycrystalline germanium has been studied from SEM/EBIC observations. The effect of two successive thermal treatments $\left(T=810^{\circ} \mathrm{C}, t=2 \mathrm{~h}\right.$ and $T=400{ }^{\circ} \mathrm{C}, t=50 \mathrm{~h}$ ) has been examined. Measurements of EBIC profiles across unactive grain boundaries were carried out at different temperatures between $140 \mathrm{~K}$ and $300 \mathrm{~K}$ and for several injection currents. The inversion of contrast observed at high injection level and low temperature has been analysed in terms of a trapping/recombination transition on a near valence band level $\left(E_{\mathrm{t}}=E_{\mathrm{v}}+0.03 \mathrm{eV}\right)$.
\end{abstract}

\section{Introduction.}

The SEM/EBIC observation mode is currently used to obtain images of electrically active defects in semiconductors. Several phenomenological models have been developed to account for the EBIC contrast of various types of defects $[1,2,3]$. On the experimental ground, most of the past studies have concerned silicon because of the high technological importance of this material. However observations of active subgrain boundaries in germanium have recently been published [4]. Following upon this work, we present in this paper new results on boundaries in germanium. The variation of contrast with injection rate is also studied at different temperatures. A contrast inversion is observed on some defects and analysed in terms of transition between

(*) Permanent address : Laboratoire de Physique du Solide, Institut de Physique, Université de Constantine, Algérie . trapping and recombination on a near valence band level.

\section{Materials and experimental conditions.}

The samples were cut out from a polycrystalline ingot grown by cooling a Ge melt contained in a graphite crucible. The material is n-type, doped with antimony at the level of $N_{\mathrm{d}} \simeq 10^{16} \mathrm{~cm}^{-3}$. Its resistivity is $0.4 \Omega . \mathrm{cm}$. The EBIC observations have been carried out on $\mathrm{Au} / \mathrm{Ge}$ Schottky barriers. Details of preparation were reported elsewhere [4]. For the thermal treatments the samples were put in sealed ampoules made of very pure silica and filled with argon at a pressure of 300 mbar. Before each anneal the electrical contacts were removed by lapping the samples with diamond polishing paste.

The EBIC observations have been made on the same part of the samples before and after annealing. Two successive treatments were performed : the first at $T=810^{\circ} \mathrm{C}$ for $2 \mathrm{~h}$ followed by quenching in air ; the second at $T=400{ }^{\circ} \mathrm{C}$ for $50 \mathrm{~h}$ also followed by quenching in air. 
3. Room temperature experiments : results and discussion.

Figure 1 shows two EBIC images of the same region of a sample before and after the $810^{\circ} \mathrm{C}$ anneal. One notes that grain boundaries which are non active in the as-grown state show a bright contrast after annealing. Near these boundaries, the EBIC current

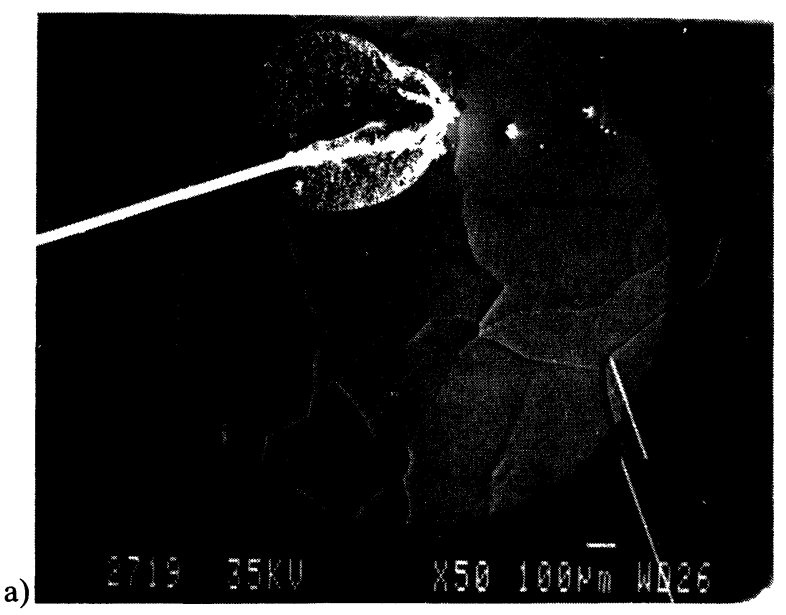

b)

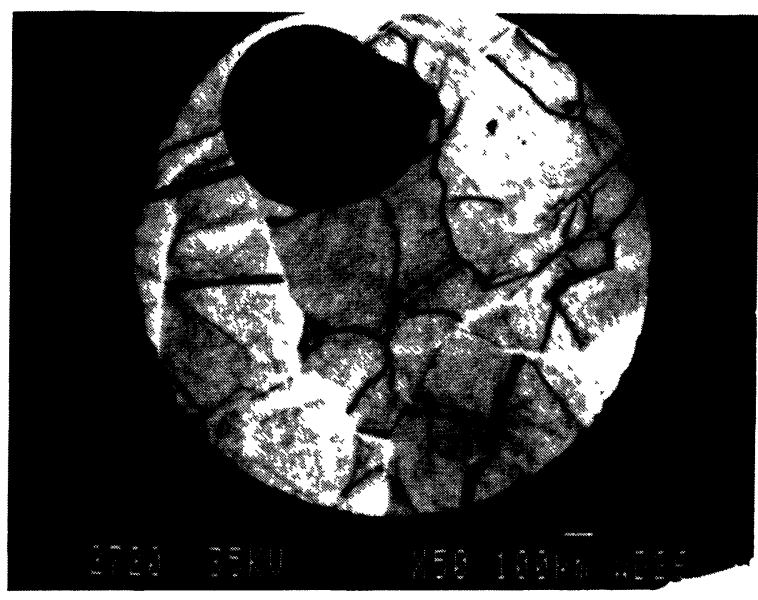

c)

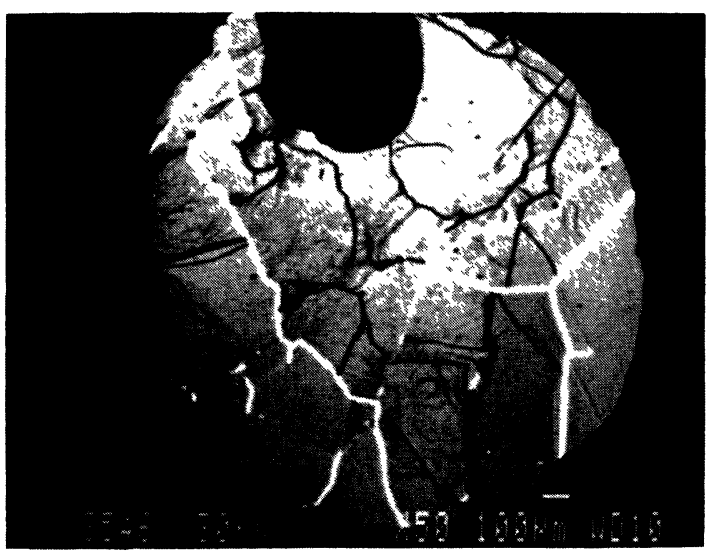

Fig. 1. - a) Secondary electron image. Some grain boundaries are made well apparent due to preferential etching by a CP4 solution used before the evaporation of circular Schottky contact (visible on the picture). b) EBIC image on the same region as in a). c) EBIC image after thermal treatment at $T=810^{\circ} \mathrm{C}$, for $2 \mathrm{~h}$. is higher than inside the grains. In order to determine the effect of annealing on minority carrier diffusion length, measurements of Schottky barrier collection efficiency have been performed inside the grains at different electron beam energies. In these experiments, the primary electron current was kept constant around $I_{0}=10^{-10} \mathrm{~A}$. The collection efficiency $\eta$ is given by :

$$
\eta=I_{\mathrm{ebic}}^{\mathrm{c}} / \mathrm{I}_{\mathrm{ebic}}^{\mathrm{G}}
$$

where $I_{\text {ebic }}^{\mathrm{c}}$ is the collected EBIC current and $I_{\mathrm{ebic}}^{\mathrm{G}}$ is the internal generated current expressed as :

$$
I_{\mathrm{ebic}}^{\mathrm{G}}=I_{0} E_{0}(1-\beta) / \varepsilon_{\mathrm{e}-\mathrm{h}}
$$

$E_{0}$ is the incident energy, $\beta$ is the fraction of energy lost by back scattering $(\beta=0.165)$ and $\varepsilon_{\mathrm{e}-\mathrm{h}}$ is the average electron-hole pair formation energy equal to $2.8 \mathrm{eV}$ in germanium [5].

The experimental variation $\eta\left(E_{0}\right)$ obtained using the geometry shown in figure $2 \mathrm{a}$, is reported in figures $2 b$ and $2 c$. The continuous curve is a theoretical fit obtained from a model which takes into accounts the presence of electrical field in the depleted zone and a possible recombination at the barrier interface [6], with the fitting parameters indicated in figure 2a. Diffusion length values of $L_{p}=13 \mu \mathrm{m}$ and $L_{p}=2.8 \mu \mathrm{m}$ are determined before and after annealing respectively.

The second thermal treatment $\left(T=400{ }^{\circ} \mathrm{C}, 50 \mathrm{~h}\right)$ has no significant influence on the electrical activity of the grain boundaries observed by EBIC : the dark and bright contrast of the active and non active boundaries respectively is maintained. Similarly, the measured diffusion length shows little variation $\left(L_{p}=4 \mu \mathrm{m}\right)$.

The bright contrast of the unactive boundaries revealed after the high temperature anneal (see Fig. 3a) can be better characterized from EBIC profiles (see Fig. 3b). Figure 3c shows several current profiles measured at room temperature for different accelerating voltages and quasi-constant beam current $\left(\simeq 10^{-10} \mathrm{~A}\right)$. The increase of EBIC signal extends over a distance of $10 \mu \mathrm{m}$ on each side of the boundary plane. The maximum contrast on the grain boundary may be defined by the relation :

$$
C_{\text {max }}=\left(I_{\mathrm{GB}}-I_{\mathrm{B}}\right) / I_{\mathrm{B}} \text {. }
$$

Where $I_{\mathrm{GB}}$ and $I_{\mathrm{B}}$ are the collected currents, respectively on the grain boundary $(x=0)$ and far from it, in the bulk. The quantity $C_{\max }$ increases linearly with the incident energy as shown in figure 4. Such variation can be accounted for by considering that two main physical parameters determine the EBIC current :

i) The width $z_{d}$ of the depleted region beneath the Schottky contact. This width is related to the local dopant concentration $N_{\mathrm{d}}: z_{\mathrm{d}} \propto\left(N_{\mathrm{d}}\right)^{-1 / 2}$. 
a)

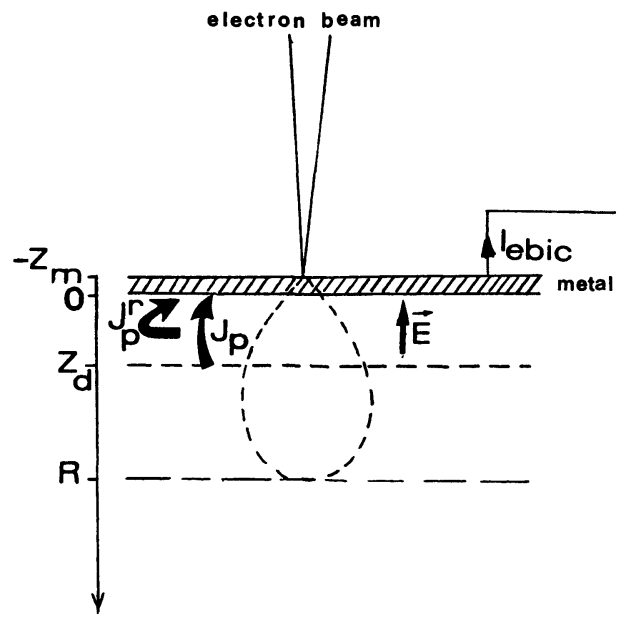

b)

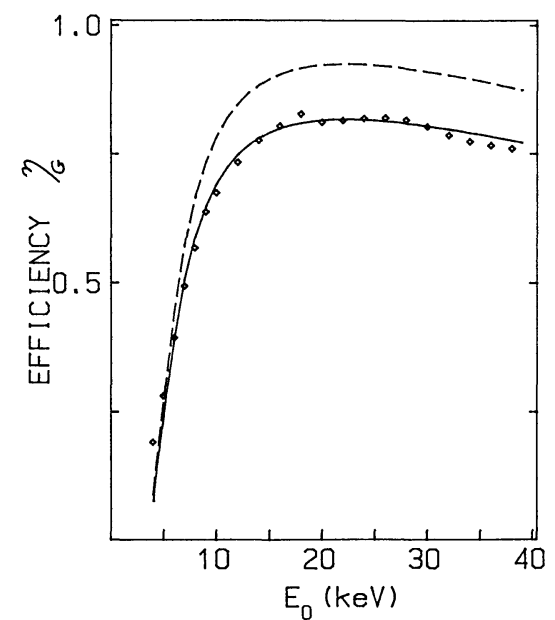

c)

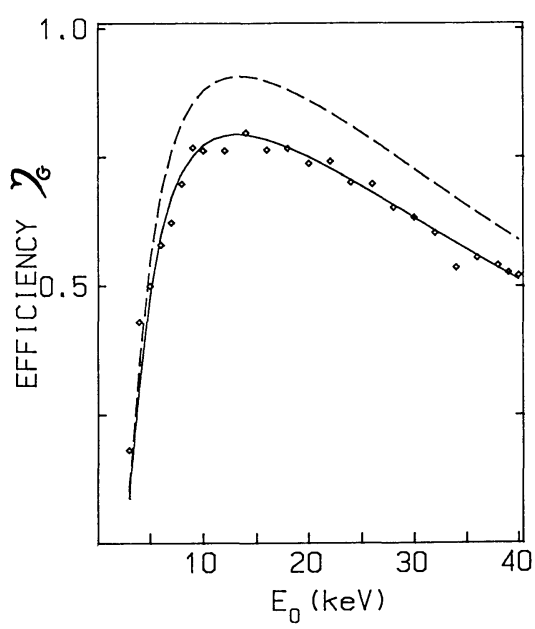

Fig. 2. - Variation of the measured collection efficiency inside the grains as a function of beam energy. a) Experimental geometry and parameters ; b) before and c) after thermal treatment at $T=810^{\circ} \mathrm{C}$, for $2 \mathrm{~h}$. The continuous curves are the result of calculations made with the following parameters : b) $L_{p}=13 \mu \mathrm{m}, z_{\mathrm{d}}=0.25 \mu \mathrm{m}$, $\left.N_{\mathrm{d}}=10^{16} \mathrm{~cm}^{-3}, z_{\mathrm{m}}=22 \mathrm{~nm}, S_{p}=5.2 \times 10^{5} \mathrm{~cm} . \mathrm{s}^{-1} . \mathrm{c}\right)$ $L_{p}=2.8 \mu \mathrm{m}, z_{\mathrm{d}}=0.25 \mu \mathrm{m}, N_{\mathrm{d}}=10^{16} \mathrm{~cm}^{-3}, z_{\mathrm{m}}=13 \mathrm{~nm}$, $S_{p}=5.2 \times 10^{5} \mathrm{~cm} . \mathrm{s}^{-1}$. The dashed curves are obtained by application of the model of Wu and Wittry [11] using the same $L_{p}, z_{\mathrm{d}}$ and $z_{\mathrm{m}}$ values as above. This corresponds to taking $S_{p}=0$ in the first model. ii) The minority carrier diffusion length $L_{p}$.

Moreover, because the high current part of the EBIC profile covers a wide zone across the boundary ( $\simeq 20 \mu \mathrm{m}$, a distance large before the size of the generation volume), the region near the defect can be considered to be a homogeneous material with properties $\left(L_{p}, z_{\mathrm{d}}\right)$ different from those inside the adjacent grains. From the collection efficiencies $\eta_{\mathrm{GB}}$ and $\eta_{\mathrm{B}}$ corresponding to the boundary and the grain respectively the maximum contrast can be evaluated :

$$
C_{\max }=\left(\eta_{\mathrm{GB}}-\eta_{\mathrm{B}}\right) / \eta_{\mathrm{B}} .
$$

Figure 4 shows that the above expression is compatible with the experimental results if diffusion lengths around the grain boundary and inside the grain take the values $L_{p}=13 \mu \mathrm{m}$ and $L_{p}=3 \mu \mathrm{m}$ respectively. The other parameters are supposed to be identical in each region $\left(N_{\mathrm{D}}=10^{16} \mathrm{~cm}^{-3}, Z_{\mathrm{d}}=\right.$ $0.25 \mu \mathrm{m})$. Such an agreement between theory an experiments cannot be obtained by assuming identical diffusion lengths $\left(L_{p}=3 \mu \mathrm{m}\right)$ but a depletion zone width $z_{\mathrm{d}}$ larger near the grain boundary than in the grains. It can be pointed out that, for high values of $L_{p}$, the collection efficiency is less sensitive to the variation of $L_{p}$ and $z_{\mathrm{d}}$. Consequently, no reliable values of $z_{\mathrm{d}}$ and $L_{p}$ near the grain boundary can be deduced from $\eta_{\mathrm{GB}}$ measurements.

The absence of contrast in the as-grown material only means that the diffusion length near the grain boundaries considered here is at least higher or comparable to the one evaluated inside the grains $\left(L_{p}=13 \mu \mathrm{m}\right)$. Thus the appearance of a bright contrast after annealing can be related to the degradation of the in-grain diffusion length.

\section{Temperature dependence of EBIC profiles.}

Observations carried out at lower temperatures down to $140 \mathrm{~K}$, make to appear a dark contrast localized in the plane of the unactive grain boundary (Fig. 5). As a result the EBIC profile is modified and shows two maximums on each side of the boundary plane. A study has been made of the conditions of appearance of this intergranular active zone by varying the temperature and the beam current intensity (Fig. 6). The transition from a one maximum profile to a two maximum profile occurs at some critical value $I_{0}^{\mathrm{c}}$ of the beam current and the lower the temperature, the smaller the value of $I_{0}^{\mathrm{c}}$. This temperature dependence suggests that a trapping centre is involved which affects the recombination mechanism of minority carriers. The simplest model to be considered involves a recombination centre setting up a carrier lifetime $\tau$, independent of the injection level, and a trapping centre of concentration $N_{\mathrm{t}}$ located at energy $E_{\mathrm{t}}$ above the valence 


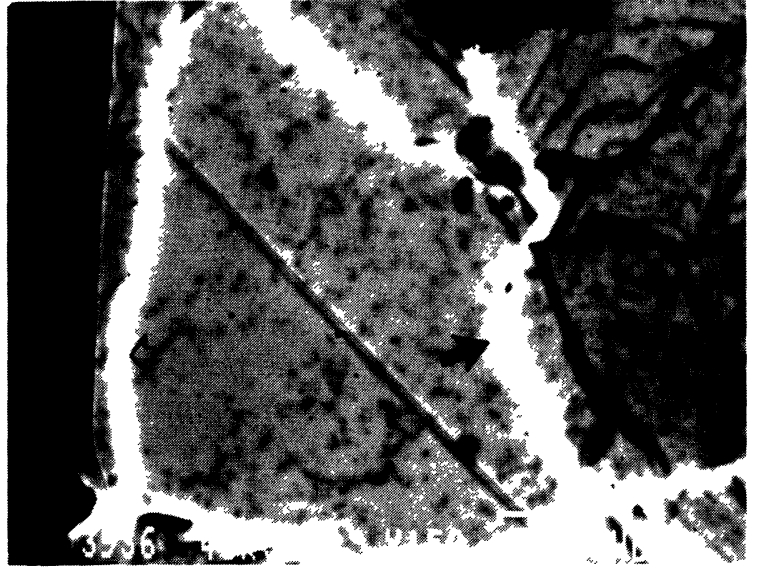

a)

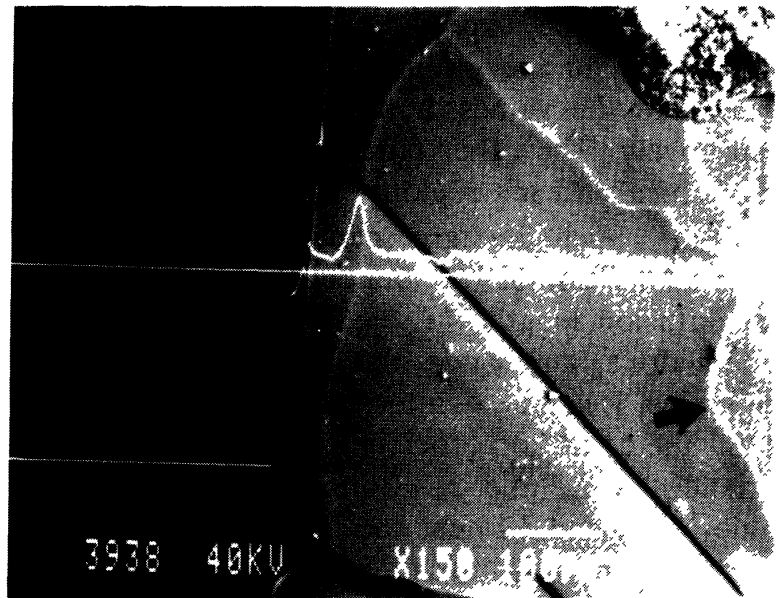

b)

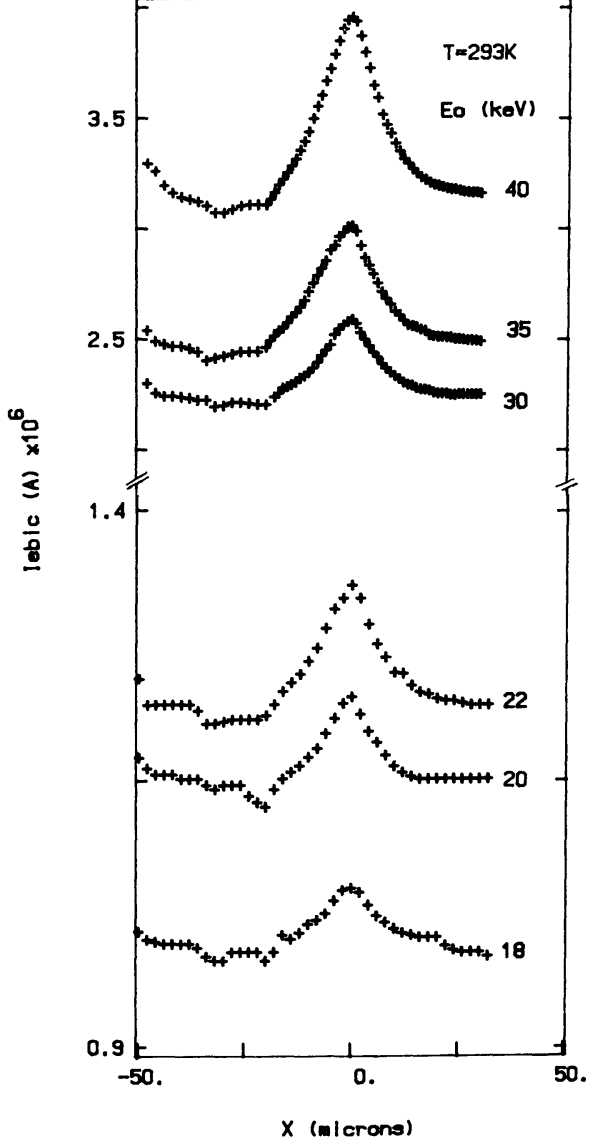

c)

Fig. 3. - a) EBIC image and b) secondary electron image of a grain boundary showing a bright contrast after the second thermal anneal $\left(T=400{ }^{\circ} \mathrm{C}\right.$ for $50 \mathrm{~h}$ ). The EBIC profile visible in $3 \mathrm{~b}$ was recorded along the straight line indicated in the same figure. c) EBIC profiles measured at different accelerating voltages.

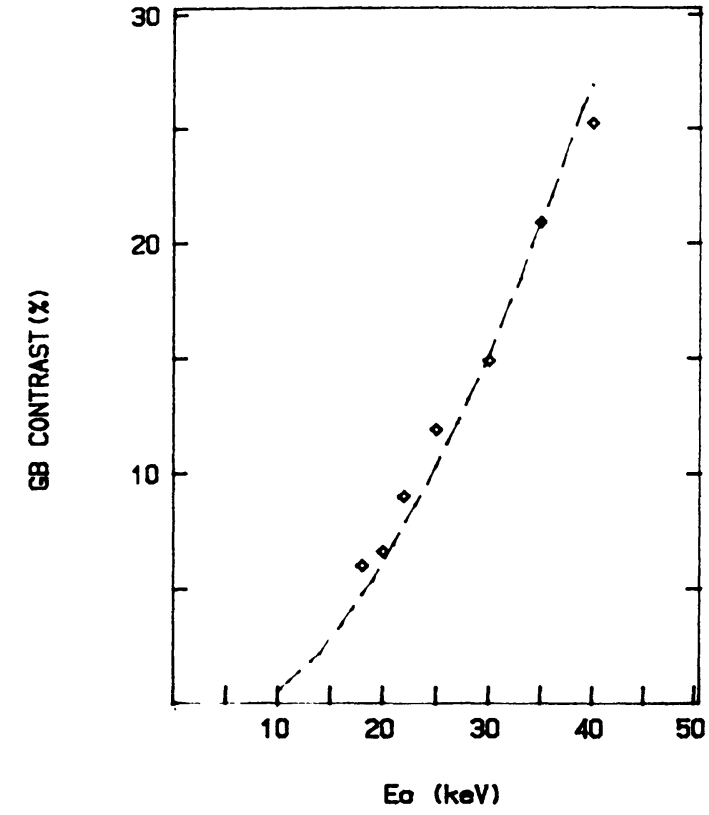

Fig. 4. - Variation with incident beam energy of the maximum EBIC contrast of an unactive boundary as deduced from the curves of figure $3 \mathrm{c}$. The dashed curve is the result of a calculation (see text).

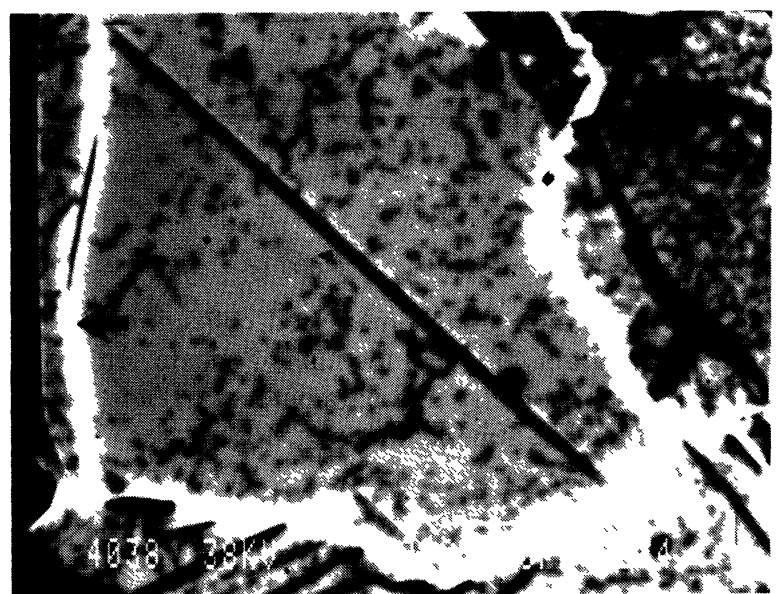

Fig. 5. - EBIC image at $T=154 \mathrm{~K}$ and for $I_{0}=10^{-9} \mathrm{~A}$, of the same region as seen in figure $3 \mathrm{a}$. Note the appearance of an intergranular active zone. 


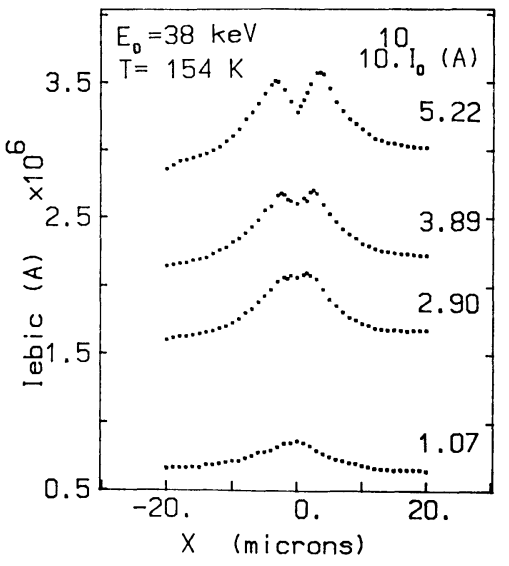

Fig. 6. - EBIC profiles measured across the boundary seen in figure 5 at $T=154 \mathrm{~K}, E_{0}=38 \mathrm{keV}$ and different values of beam current.

band. Under continuous generation rate $g$, the effective hole lifetime $\tau_{p}$ is given by :

$$
\frac{1}{\tau_{\mathrm{p}}}=\frac{g}{p}=\frac{1}{\tau}+\gamma_{p}\left[n_{\mathrm{t}}-\frac{p_{1}}{p}\left(N_{\mathrm{t}}-n_{\mathrm{t}}\right)\right] .
$$

The last term represents the difference between the capture rate of the free holes $p$ (capture coefficient $\gamma_{p}$ ) on the trapped electrons $n_{\mathrm{t}}$ and the thermal emission rate of the trapped holes $\left(N_{\mathrm{t}}-n_{\mathrm{t}}\right) ; p_{1}$ is the usual reference hole concentration expressed as $p_{1}=N_{\mathrm{v}} \exp \left(-E_{\mathrm{t}} / k T\right)$, where $N_{\mathrm{v}}$ is the effective density of states in the valence band. At low injection level and high temperature, the capture flux is equilibrated by the thermal emission flux that defines the behaviour of a true trapping centre and the lifetime takes the value $\tau$. At high injection level and low temperature, the recombination of the free electrons $n$ (capture coefficient $\left.\gamma_{n}\right)$ with the trapped holes $\left(N_{\mathrm{t}}-n_{\mathrm{t}}\right)$ represents a significant contribution to the charge balance of the centre :

$$
\gamma_{p} n_{\mathrm{t}} p=\gamma_{p} p_{1}\left(N_{\mathrm{t}}-n_{\mathrm{t}}\right)+\gamma_{n} n\left(N_{\mathrm{t}}-n_{\mathrm{t}}\right) .
$$

Under these conditions the last term in equation (5) increases which lead to a decrease of the effective lifetime $\tau_{p}$ with injection level. This explains the sublinear variation of the collection efficiency $\eta_{\mathrm{GB}}$ with beam current which gives rise to a relative minimum in the profile. The critical generation rate $g_{\mathrm{c}}$ above which the effective lifetime is reduced below the value $\tau$ can be expressed in a simple quantitative form by assuming that $\gamma_{n}=\gamma_{p}=\gamma$ and $N_{\mathrm{t}}<N_{\mathrm{d}}+p_{1}$

$$
2 g_{\mathrm{c}} \tau=\left(N_{\mathrm{d}}-N_{\mathrm{t}}\right)\left(1+\gamma \tau N_{\mathrm{t}}\right)+p_{1} .
$$

Such a relationship can be tested by plotting the logarithm of the experimental quantity $I_{0}^{\mathrm{c}} T^{-3 / 2}$ as a function of reciprocal temperature (Fig. 7). A linear

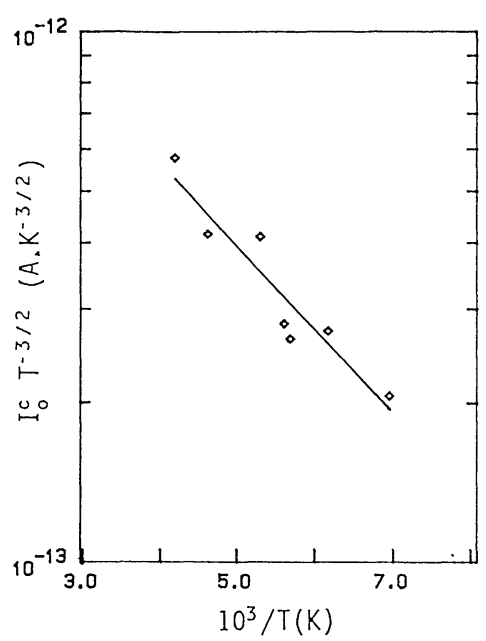

Fig. 7. - Graphical representation of the variation of the critical current $I_{0}^{\mathrm{c}}$ as a function of temperature. The trap level $E_{\mathrm{t}}$ is given by $E_{\mathrm{t}}=-\mathrm{d}\left[\ln \left(I_{0}^{\mathrm{c}} T^{-3 / 2}\right) / \mathrm{d}(1 / k T)\right]$.

variation is obtained from which a value $E_{\mathrm{t}}=0.03 \mathrm{eV}$ is deduced. This small value accounts for the fact that $p_{1}$ is the dominant term in the second hand of equation (7) $\left(p_{1}=2 \times 10^{18} \mathrm{~cm}^{-3}\right.$ at $T=300 \mathrm{~K})$.

With regard to the nature of the grain boundaries considered here, one can notice that the defects presenting a bright contrast are generally random grain boundaries with large misorientation. On the other hand, subgrains are most frequently active (dark contrast). This distinction leads to think that the unactive boundaries have been passivated with impurities segregating during the cooling of the melt. SIMS analysis have revealed the presence of aluminium rich precipitates inside the grains while the role of $\mathrm{Al}$ in the passivation of grain boundaries in silicon is well known [7 to 10]. Chemical analysis by STEM are needed to confort our hypothesis and eventually allow to identify the defect responsible of the observed trapping centre.

\section{Conclusion.}

SEM observations in the EBIC mode have allowed us to study the influence of thermal treatments on the electrical activity of grain boundaries with respect to grain volume in germanium. The analysis of EBIC profiles measured across the grain boundaries as a function of temperature and injection level has given evidence of the presence of a particular hole trapping centre in the plane of some unactive grain boundaries.

\section{Acknowledgements.}

The authors wish to thank Dr. P. Derouet of Minemet-Recherches (Trappes - France) for providing the $\mathrm{Ge}$ samples. 


\section{References}

[1] Donolato C., Optik 52 (1978/1979) 19 and J. Appl. Phys. 54 (1983) 1314.

[2] Marek J., J. Appl. Phys. 53 (1982) 1454.

[3] Pasemann L., Phys. Stat. Sol. (a) 84 (1984) 13.

[4] Tabet N. and Monty C., Philos. Mag. B 57 (1988) 763.

[5] Klein C. A., Phys. Lett. A 24 (1967) 513.

[6] Tabet N., Tarento R. J., Philos. Mag. B 59 (1988) 243.

[7] Kazmerski L. L. and Russel P. E., in « Colloque International sur les semiconducteurs polycristallins », J. Phys. Colloq. France 43 (1982) C1-171.
[8] Sunderasen R., Fossum J. G. and Burk D. E., J. Appl. Phys. 55 (1984) 1162.

[9] Zehaf M., Mathian G., Pasquinelli M., MarTINUZZI S., in «Polymicrocrystalline and amorphous semiconductors », P. Pinard and S. Kalbitzer Eds. (Les Editions de Physique) 1985, p. 137.

[10] Maurice J.-L., Revue Phys. Appl. 22 (1987) 613.

[11] Wu C. J., Wittry D. B., J. Appl. Phys. 49 (1978) 2827. 